\title{
Covid-19: Test and trace system is not fit for purpose, says Independent SAGE
}

\author{
Jacqui Wise \\ London
}

The government's test, track, and trace system needs a radical overhaul because it is "not fit for purpose," an independent group of experts has said.

A draft report from the Independent Scientific Advisory Group for Emergencies (iSAGE) says that the government must urgently pivot away from a centralised system to one that is led locally and coordinated by directors of public health. ${ }^{1}$ The report was discussed at a public consultation on 9 June, and a final report is due to be presented to the government next week.

The report from a group of 12 leading scientists urges the government to adopt a model designed to find, test, trace, isolate, and support (FTTIS), already used by public health authorities in cases of tuberculosis, meningitis, foodborne outbreaks, and some other infections.

The FTTIS model should be embedded as much as possible within existing networks and make full use of GPs, local hospital laboratories, health commissioners, school nurses, and environmental health officers, said iSAGE.

\section{Concerns over access}

David King, a former chief scientific adviser and iSAGE chair, said, "The government has placed huge emphasis on their test, track, and trace system in recent weeks, even labelling it "world beating.' It is clear from our research that this simply isn't the case-indeed, the system as it stands is not fit for purpose. This is the critical moment for the government to act now or risk further spikes."

Dido Harding is in charge of implementing the government's centralised test, track, and trace system, with private contractors providing 23000 contact tracers. However, iSAGE notes that Harding told the health and social care select committee that this was unlikely to be fully operational until September.

The report says that the system can work only with sufficient access to rapid testing, but there are multiple concerns that this is not the case in England. The centralised contact tracing system is "untested and being operated by companies with no experience in this area," warns iSAGE. It also criticises the "apparent failure of the app" designed to help identify contacts of people who have covid-19. The report points out that, when the app was planned, it was hailed by ministers as being essential, whereas now it is described as of marginal importance. The report adds that eliminating covid-19 will need at least $80 \%$ of all close contacts of infected people to remain isolated for
14 days so that they cannot pass on the infection. "This is clearly not happening," it states.

\section{General practice}

Anthony Costello, director of the Institute for Global Health, University College London, told a press briefing, "The key thing is to isolate the people who have got the infection quickly. Just focusing on the testing and tracing side of it is doomed to fail."

If there are 5000 infections a day and 10 close contacts per person then 50000 contacts should be traced each day, iSAGE says. However, it seems that far fewer contacts have been traced, and there are numerous reports of contact tracers left twiddling their thumbs. The health select committee has asked Harding for data on the number of contacts actually traced, and the figures are expected to be released later this week. ${ }^{2}$

Costello has said that GPs are best placed to reassure patients who have covid-19 symptoms and to monitor them for long term sequelae. "GPs are the backbone of the NHS. The idea that we would exclude GPs from this is absurd," he said.

Gabriel Scally, president of the Epidemiology and Public Health Section at the Royal Society of Medicine, commented, "It is absolutely critical for general practice to be involved. It is amazing that all of this NHS resource and capacity is not being used."

In response, a Department of Health and Social Care spokesperson said, "This report fails to acknowledge [that] the recommendations it makes have either already been implemented or are under way. We have built up an entire testing industry in a matter of weeks and are now helping thousands of people book a test, isolate, and share their recent close contacts, with anyone who needs a test able to get one."

The spokesperson said that local governments were already working with Public Health England to investigate and control outbreaks, adding, "To further support the rollout we are providing $£ 300 \mathrm{~m}$, alongside comprehensive support, to assist councils in developing outbreak control plans for their areas."

Independent SAGE. Towards an integrated find, test, trace, isolate, support (FTTIS) response to the pandemic. Jun 2020. https://www.independentsage.org/wp-content uploads/2020/06/IndependentSAGE-report-4.pdf.

2 Griffin S. Covid-19: Lack of test and trace data are frustrating government scrutiny. BMJ 2020;369:m2239. 10.1136/bmj.m2239 32499391

This article is made freely available for use in accordance with BMJ's website terms and conditions for the duration of the covid-19 pandemic or until otherwise determined by BMJ. You may use, download and print the article for any lawful, non-commercial purpose 
